\title{
Rural-based Science, Technology, Engineering and Mathematics teachers' and learners' acceptance of mobile learning
}

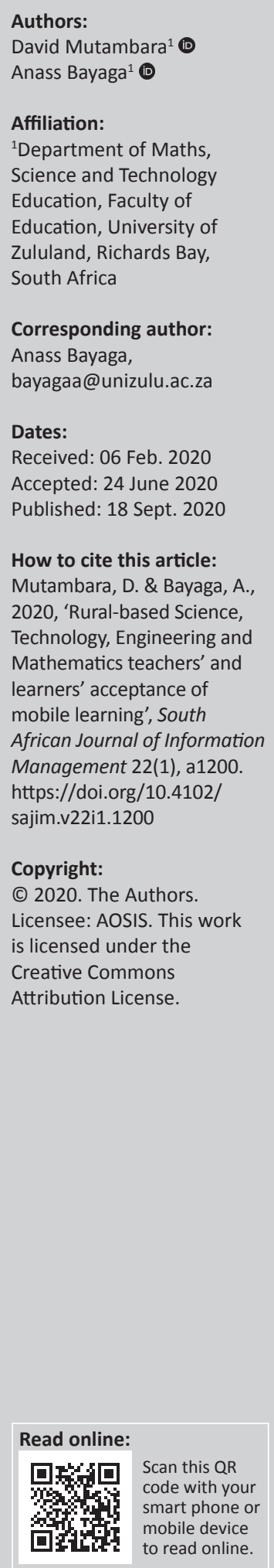

Background: Science, Technology, Engineering and Mathematics (STEM) is faced with many challenges resulting in learners' poor performance at matriculation level in South Africa. However, prior research has shown that mobile learning (m-learning) can be used to alleviate the challenges of STEM education. Prior research focused on tertiary institutions' students and lecturers, in developed countries. However, very little is known about rural school STEM teachers' and learners' acceptance of m-learning.

Objectives: The article investigates factors that rural-based STEM teachers and learners consider important when adopting mobile learning. Furthermore, the study also seeks to examine if there is a statistically significant difference between teachers' and learners' acceptance of mobile learning.

Method: The research employed a quantitative approach. Stratified random sampling was used to select 350 teachers and learners to participate in the survey. Valid questionnaires received were 288 (82\%), and data were analysed using partial least squares structural equation modelling.

Results: The proposed model explained $64 \%$ of the variance in rural-based STEM teachers' and learners' behavioural intention to use m-learning. Perceived attitude towards use was found to be the best predictor of teachers' and learners' behavioural intention. The results also showed no significant difference between teachers' and learners' path coefficients.

Conclusion: The research recommends that awareness campaigns, infrastructure, mobile devices and data need to be made available for m-learning to be successfully adopted in rural areas.

Keywords: technology acceptance model; perceived social influence; perceived resources; STEM; perceived usefulness; perceived ease of use; perceived ease to collaborate.

\section{Introduction}

Science, Technology, Engineering and Mathematics (STEM) Task Force (2014:9) in America adopts the view that STEM education is far more than a 'convenient integration of its four disciplines; rather, it encompasses 'real-world, problem-based learning' that integrates the disciplines through cohesive and active teaching and English learning approaches'. What can be learnt from this view is that STEM education aims at teaching learners to solve real-world problems, collaborate and integrate these four disciplines rather than learning these disciplines in isolation, just as they do not exist in isolation in the real world.

However, STEM is faced with many challenges resulting in learners' poor performance at the matriculation level in South Africa. According to Bosman and Schulze (2018), this poor performance is because of the mismatch between the teaching style and the learners' learning styles in the classroom. Bosman and Schulze (2018) suggest that teachers are still using traditional face-to-face instruction, which can only cater for $20 \%$ of the class and fails to stimulate deep holistic learning experiences. On the other hand, Visser, Juan and Feza (2015) attribute this poor performance, particularly in rural areas, to lack of textbooks and learning material. Additionally, Mboweni (2014) blamed poor performance in STEM-related subjects to a high rate of learner absenteeism. Mboweni (2014) noted among others, poverty, HIV/AIDS, social grants pay out days, lack of parental involvement, teenage pregnancy and unstable family backgrounds as the leading causes of learners' absenteeism in rural areas. Based on the aforementioned studies, one can conclude that there is no effective teaching and learning of STEM-related subjects in rural areas. 
Regardless of the work of Bosman and Schulze (2018), Visser et al. (2015) and Mboweni (2014) on the challenges of STEM education, prior studies have also shown that mobile learning (m-learning) can be used to mitigate these challenges (Alrajawy et al. 2017; Bourgonjon, Valcke \& Soetaert 2010; Criollo-C, Luján-Mora \& Jaramillo-Alcázar 2018). There are several reasons attributed to the need for m-learning, hence this study. The view is that m-learning increases contact time between teachers and learners (Alrajawy et al. 2017). Another view is that through the use of m-learning, absent learners can still learn what was covered as content can be made available anywhere and anytime, as learning will be no longer confined to the classroom. Consequently, Bourgonjon et al. (2010) noted that m-learning changes lessons from teacher-centred to learner-centred. Accordingly, m-learning provides teachers with different pedagogies such as educational games, quiz and access to mobile virtual worlds to cater to different learners' needs. Furthermore, m-learning brings many advantages into the classroom such as making study material available to learners anytime and anywhere (Criollo-C et al. 2018).

Lessons that can be drawn from the studies (Alrajawy et al. 2017; Bourgonjon et al. 2010; Criollo-C et al. 2018) are that even though rural high school STEM education is faced with challenges such as lack of learning material and textbooks, teaching and learning styles mismatch, and high rate of learner absenteeism, learners can still benefit from m-learning as they will be able to have easy and fast access to learning material anytime and anywhere. Additionally, m-learning will enable teachers to vary their teaching styles, to meet the learning needs of different learners.

Sánchez-Prietoa et al. (2019) stated that the rate of adoption of m-learning into the classroom is far below the expected level considering the benefits it brings into the classroom. Users' attitude is key for any acceptance of any information system (IS) (Davis 1989). Based on the assessment by Davis (1989), one can argue that the acceptance of m-learning in rural high schools depends on learners' and teachers' attitudes towards it.

A plethora of studies has been conducted to identify factors that affect the acceptance of m-learning (Bourgonjon et al. 2010; Nikou \& Economides 2018; Sánchez-Prietoa et al. 2019; Saroia \& Gao 2019; Sivo, Ku \& Acharya 2018). However, most of these studies focused on tertiary institutions' students (Sánchez-Prietoa et al. 2019; Saroia \& Gao 2019; Sivo et al. 2018) and lecturers (Al-dheleai et al. 2019; MacCallum \& Jeffrey 2014). It can be urged that for m-learning to be successfully implemented in rural high schools, a lot of acceptance studies need to be carried out. However, very few acceptance studies were carried out in high schools, especially in the rural African context (Bourgonjon et al. 2010; Nikou \& Economides 2018).

Despite previous studies conducting investigations on high school teachers and learners' acceptance of m-learning
(Bourgonjon et al. 2010; Nikou \& Economides 2018; Siyam 2019), these studies focused on the acceptance of mobile assessment (Nikou \& Economides 2018), special education (Siyam 2019) and acceptance of digital game-based learning (Bourgonjon et al. 2010). All these studies were carried out in urban areas of developed countries.

Very little is known about the rural school STEM teachers' and learners' acceptance of m-learning. According to Ford and Botha (2010), South Africa should carry out its acceptance studies and should not blindly follow examples from developed countries. Based on the argument thus far, this study sought to examine the rural high schools STEM teachers' and learners' perceptions towards m-learning. This is primarily because, collectively, Nikou and Economides (2018) and Bourgonjon et al. (2010) did not focus on the perceptions of rural high school STEM teachers' and learners' attitude towards m-learning. Additionally, they did not compare teachers' and learners' perceptions of m-learning.

Identifying and understanding factors that rural high school STEM teachers and learners consider important in adopting m-learning is key to its successful implementation. Therefore, this study used the technology acceptance model (TAM) to investigate the factors that influence rural high school STEM learners' and teachers' behavioural intention (BI) to use m-learning for STEM learning. Specifically, this study aimed to give answers to the following research questions (RQs):

RQ1: What is the effect of teachers' and learners' perceived usefulness, perceived ease of use, perceived attitude towards the use, perceived resources (PR), perceived ease to collaborate (PETC) and perceived social influence (PSI) on their behavioural intention to use m-learning?

RQ2: Is there a statistically significant difference between rural based STEM teachers' and learners' acceptance models?

For the study to be able to sufficiently provide answers to these two RQs, this study proposes and validates a hypothetical model that combines psychosocial, behavioural and technology-related elements. The findings of this study may provide more insight on high school teachers' and learners' m-learning acceptance and help policy-makers and the Department of Basic Education (DBE) on how to successfully implement m-learning in rural areas.

\section{Literature review and model development Technology acceptance model variables}

In attempting to identify and understand factors that affect users' acceptance of ISs, several models have been proposed (Davis 1989; Fishbein \& Ajzen 1975; Venkatesh et al. 2003; Venkatesh \& Davis 2000). However, in the m-learning context, TAM and the Unified Technology of Acceptance and Use Theory (UTAUT) are the commonly used models. Venkatesh et al. (2003) criticised UTAUT for its failure to predict behaviours that are not completely within an individual's 
volitional control. M-learning can be implemented, and teachers and learners can be forced to use it. As UTAUT cannot predict the behaviours that are beyond an individual's control, it cannot be used in this study. The TAM was selected because it is considered to be robust in predicting users' technology acceptance in many different contexts and is the commonly used model in the study of acceptance of m-learning (Nikou \& Economides 2018; MacCallum \& Jeffrey 2014; Siyam 2019).

The TAM was developed for elucidation and predicting users' acceptance of IS by examining users' attitudes and beliefs (Davis 1989). The model proposes that perceived usefulness (PU) and perceived ease of use (PEOU) are the main pillars that determine users' attitudes towards the use of an IS. Perceived attitude towards (ATT) the use of an IS to determine BI, which subsequently impacts the actual use of IS (Siyam 2019). Venkatesh et al. (2003) suggested that more variables that are context related should be added to the TAM, to improve its explanatory power of the acceptance of the technology in question (Li et al. 2019).

\section{Behavioural intention to use}

Fang, Kayad and Misieng (2019:18) defined BI as, 'the cognitive representation of a person's readiness to perform a given behaviour'. Behavioural intention is considered to be the best single predictor of behaviour (Davis 1989; Venkatesh 2000). In the m-learning context, the study by Joo, Kim and Kim (2016) confirmed the findings of Venkatesh (2000) and Davis (1989) who collectively reported that users' BI predicts the actual usage.

\section{Perceived attitude towards}

Siyam (2019) defined attitudes as the user's feelings and views towards a psychological matter. Thoughts and feelings play a very important part in rejecting or accepting an IS. Several studies have found that teachers and learners have positive attitudes towards m-learning (Joo et al. 2016; Osakwe, Nomusa \& Jere 2017; Siyam 2019). This study aims at investigating rural-based STEM teachers' and learners' attitudes towards m-learning. The following hypothesis answers the first RQ:

H1: Rural-based STEM teachers' and learners' ATT the use has a positive influence on their BI to use m-learning.

\section{Perceive usefulness}

Cheng (2019) defined PU in the m-learning context as a person's perception that using m-learning will improve his or her teaching or learning. One of the main reasons why teachers and learners adopt m-learning is their perception that it will improve teaching and learning (Joo et al. 2016; Osakwe et al. 2017; Siyam 2019). Siyam (2019) studied the effect of special education teachers' PU on their ATT and BI. Siyam (2019) found that special education teachers' PU positively affects their ATT and BI. Their results were also consistent with Alshmrany and Wilkinson (2017) who found that learners' PU directly affects their ATT and BI. If ruralbased STEM teachers and learners anticipated improvement of performance in STEM-related subjects as a result of using m-learning, their attitude towards it will be more positive. Hypotheses $\mathrm{H} 2$ and $\mathrm{H} 3$ are as follows:

H2: Rural-based STEM teachers' and learners' PU significantly and positively affects their ATT the use of m-learning.

H3: Rural-based STEM learners' and teachers' PU significantly and positively affects their BI to use m-learning.

\section{Perceived ease of use}

Perceived ease of use was defined as the extent to which an individual believes that adopting a particular IS would be free from effort (Davis 1989). There is some contradiction in the body of knowledge on the effect of PEOU on BI (Saroia \& Gao 2019; Siyam 2019). Saroia and Gao (2019) found that PEOU does not necessarily have a direct effect on BI, while Siyam (2019) reported that PEOU has a positive direct effect on BI. Perceived ease of use has a positive effect on PU and ATT (Saroia \& Gao 2019). If high school STEM teachers and learners could experience m-learning and find it easy to use, they would be likely to find m-learning useful and develop a positive BI to use m-learning for learning STEM-related subjects. Hypotheses $\mathrm{H} 4-\mathrm{H} 6$ are as follows:

H4: Rural-based STEM teachers' and learners' PEOU has a positive effect on their PU.

H5: Rural-based STEM teachers' and learners' PEOU has a positive effect on their BI to use.

H6: Rural-based STEM teachers' and learners' PEOU has a positive effect on their ATT the use.

\section{Perceived resources}

Perceived resources is defined as the extent to which an individual believes that he or she has the personal and organisational resources needed to use an IS'. (Mathieson, Peacock \& Chin 2001:89). The availability of the resources influences a user's perception of the difficulty or ease of performing a task using an IS (Alshmrany \& Wilkinson 2017). In rural high schools, resources needed for m-learning include mobile devices, network connectivity, computer technical support and mobile platforms. Perceived resources was found to have a positive effect on PU, PEOU and ATT (Lim \& Khine 2006; Sivo et al. 2018; Teo, Lee \& Chai 2008). Lim and Khine (2006) investigated the effects of the availability of resources on teachers' acceptance of information and communication technology (ICT) into the classroom. They found that lack of laptops, computer technical support and support from peers negatively affected the integration of ICT into the classroom. Ruralbased STEM teachers' and learners' PR has a significant effect on their PEOU and influence their BI to use m-learning. Without a supportive environment, it is very difficult for rural high school STEM teachers and learners to plan to adopt m-learning, regardless of how much they 
might like to (Mutambara \& Bayaga 2020). Hypotheses H7-H9 are as follows:

H7: Rural-based STEM teachers' and learners' PR has a positive effect on their BI to use m-learning.

H8: Rural-based STEM teachers' and PR has a positive effect on their PEOU.

H9: Rural-based STEM teachers' and PR has a positive effect on their ATT the use.

\section{Perceived social influence}

Perceived social influence is similar to the theory of reasoned action's subjective norm (Fishbein \& Ajzen 1975:45), which was defined as 'a person's perception that most people who are important to him or her think that he or she should or should not perform the behaviour in question'. In this study, PSI is when rural high school STEM learners and teachers consider the opinion of those who are important to them whether they should or should not use m-learning. Learners and teachers in rural areas are influenced by messages about m-learning. This was suggested by Venkatesh (2000) who stated that people internalise the views of other people and make them part of their belief system. If STEM teachers and learners think that their community, learner's parents and department officials are expecting them to use m-learning, they would have a positive attitude towards m-learning. Hypotheses $\mathrm{H} 10-\mathrm{H} 12$ are as follows:

H10: Rural-based STEM teachers' and learners' PSI has a positive effect on their PU

H11: Rural-based STEM teachers' and learners' PSI has a positive effect on their ATT to the use of m-learning.

H12: Rural-based STEM teachers' and learners' PSI has a positive effect on their PEOU.

\section{Perceived ease to collaborate}

In a collaborative learning environment, learners are encouraged to be interdependent, and every learner is accountable for his or her own and others' learning process (Dillenbourg 1999). This is achieved by giving learners the chance to receive other learners' perspectives and enhance an individual's critical thinking skills by comparing and evaluating opposing viewpoints (Liu 2016). Studies show that m-learning supports collaborative learning, and it enhances individual knowledge development, as well as group knowledge sharing (Bazelais \& Doleck 2018; Demir \& Akpinar 2018; Padmanathan \& Jogulu 2018). When rural-based STEM teachers and learners perceive that it is easy to collaborate in an m-learning environment, they are likely to realise the usefulness of m-learning. Hypothesis $\mathrm{H} 13$ is as follows:

H13: Teachers' and learners' PEC has a positive effect on their PU of m-learning.

Based on the theoretical underpinning and what prior studies have established, a hypothetical model is shown in Figure 1. Figure 1 shows the model used in this study to examine rural-based STEM teachers' and learners' acceptance of mobile learning.

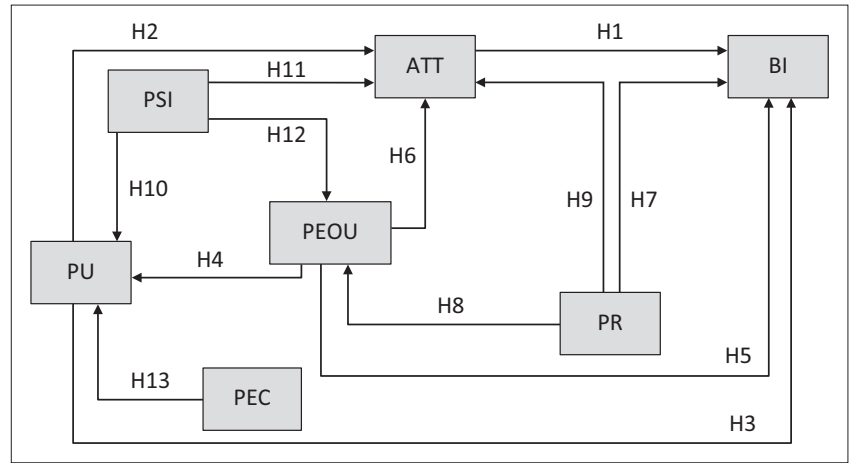

ATT, attitude; $\mathrm{BI}$, behavioural intention; PEC, perceived ease to collaborate; PEOU, perceived ease of use; PR, perceived resources; PSI, perceived social influence; PU, perceived usefulness.

FIGURE 1: Hypothetical model of rural-based Science, Technology, Engineering and Mathematics learners' and teachers' acceptance of mobile learning.

\section{Methods \\ Research design}

This study employed a survey design. According to Creswell (2013), a survey design provides a quantitative description of attitudes or opinions of a population by studying a sample of that population. In this study, a survey design was used to provide a quantitative description of rural-based STEM teachers' and learners' attitudes towards mobile learning. The survey design was preferred in this study as it was cheap, and it provides rapid turnaround in data collection. The data were collected at one point in time (cross-sectional survey). A questionnaire was used to collect data. Demographic and opinion-related data were collected from grade 12 STEM teachers and learners using a questionnaire. First, descriptive statistics were used to analyse data from the respondents. Second, partial least squares-structural equation model (PLSSEM) was used to test the model.

\section{Participants}

To collect data, this study adopted stratified random sampling, where all rural high schools in King Ceshwayo District were grouped using their quintiles. To ensure that homogenous elements form a stratum, schools in the same quintile were grouped. Schools in rural areas fall into three quintiles, and thus, three strata were formed. Simple random sampling was then used to select four schools in each stratum. Two hundred grade 12 STEM learners were then shortlisted from the selected schools using simple random sampling. Simple random sampling was also used to select 150 STEM teachers. The selected respondents were given questionnaires and $288(82 \%)$ valid questionnaires were collected. Of the 288 valid questionnaires, $176(61 \%)$ were collected from ruralbased STEM learners, and the remaining 112 (39\%) were from rural-based STEM teachers. The range of the age of learners was 17 to 21 . There were 73 (41\%) female STEM learners who took part in the study and the remaining 103 (59\%) were male learners.

In this study, $61(54 \%)$ rural-based STEM teachers who responded to the questionnaires were men, while $51(46 \%)$ 
were women. Of the 112 teachers who participated, 21 (19\%) of them were less than 30 years, 28 (25\%) were between 30 and 40 years, $43(38 \%)$ were between 40 and 50 years and $20(18 \%)$ were above 50 years old.

Perceived ease of use was the construct with most items. Perceived ease of use had five items. Using Hair et al.'s (2017) recommendation of 10 times larger than the number of items of the construct with most items, the recommended minimum sample size is 50 . The sample size of this study exceeds the recommended 50 .

\section{Measures}

The questionnaire was divided into two sections. Section A required the respondents to fill in their demographical information. In Section B, rural-based STEM teachers and learners answered the main part of the questionnaire, which comprised scales measuring the constructs of the proposed model. Items to measure BI, PEOU and PU were adapted from previously validated and reliable instruments (Alrajawy et al. 2018). To measure ATT, PSI and PR, this study adapted items from Sivo et al. (2018), Siegel (2008) and Venkatesh et al. (2003) and modified them to suit the needs of this study. The items of the construct perceived ease to collaborate (PEC) were newly created in this study. The measurement instrument consists of 7 constructs (BI, PEOU, PU, PR, ATT, PSI and PEC) making a total of 24 items. All items were measured on a 7-point Likert-type scale with 1 corresponding to 'strongly disagree' and 7 to 'strongly agree'.

\section{Analysis technique}

Partial least squares structural equation modelling was used to analyse data making use of the software SmartPLS 3. Partial least squares-structural equation model was used for predicting rural-based STEM teachers' and learners' BI to use $\mathrm{m}$-learning and to assess if there was a significant difference between teachers' and learners' acceptance of m-learning. The study followed a two-step approach to model analysis (Hair et al. 2017). First step is the evaluation of reliability and validity of the construct measures. In the next step, the relationships within the inner model was evaluated by assessing the significance of the relationships, predictive power of different variables and explained variance of the dependent variables (Hair et al. 2017).

\section{Ethical consideration}

The study received ethical clearance from the University of Zululand Research Ethics Committee. Number: UZREC 171110-030.

\section{Data analysis results Measurement model assessment}

The measurement model describes the association between indicators and the latent variables. Following the suggestion by Hair et al. (2017) of assessing reflectively measurement models, the study examined composite reliability (CR), outer loadings, average variance extracted (AVE) and discriminant validity. First, the factor loadings and CR were used to test for item reliability and convergent validity, respectively. The results (Table 1 ) showed that almost all outer loadings were higher than 0.7 (Chin 1998) except PSI3 (0.646). The item was not removed because of the exploratory nature of the study and removing it did not increase the CR (Garson 2016). Items that were removed from the model because of having outer loadings lower than 0.7 were: PEOU4, PEOU5, ATT5, PR3 and PEC3. When these items were removed from the model, the CR of their respective constructs increased above the recommended threshold of 0.7 (Hair et al. 2017). The results confirmed item reliability. Composite reliability values show the extent to which the items indicate the latent variable. Table 1 shows that all the CR values exceeded the recommended value of 0.7 (Garson 2016). Second, the AVE values were used to assess convergent validity. Convergent validity assesses the degree to which measures of the same constructs positively correlates with each other (Hair et al. 2017). The AVE values indicate the average commonality for each construct in a reflective model (Chin 1998). All the AVE values were greater than the recommended 0.5 (Garson 2016). Third, the Heterotrait-Monotrait ratio of correlations (HTMT) and the Fornell-Larcker criterion were used to assess discriminant validity. Discriminant validity assesses the degree to which a construct is truly different from other

TABLE 1: Measurement model.

\begin{tabular}{|c|c|c|c|c|}
\hline Construct & Items & Loading & CR & AVE \\
\hline \multirow{4}{*}{$\begin{array}{l}\text { Perceived social } \\
\text { influence (PSI) }\end{array}$} & - & - & 0.819 & 0.604 \\
\hline & PSI1 & 0.850 & - & - \\
\hline & PSI2 & 0.820 & - & - \\
\hline & PSI3 & 0.646 & - & - \\
\hline \multirow{6}{*}{$\begin{array}{l}\text { Perceived } \\
\text { usefulness (PU) }\end{array}$} & - & - & 0.916 & 0.645 \\
\hline & PU1 & 0.824 & - & - \\
\hline & PU2 & 0.815 & - & - \\
\hline & PU3 & 0.827 & - & - \\
\hline & PU4 & 0.793 & - & - \\
\hline & PU5 & 0.829 & - & - \\
\hline \multirow{3}{*}{$\begin{array}{l}\text { Perceived ease to } \\
\text { collaborate (PEC) }\end{array}$} & - & - & 0.894 & 0.808 \\
\hline & PEC1 & 0.889 & - & - \\
\hline & PEC2 & 0.908 & - & - \\
\hline \multirow{4}{*}{$\begin{array}{l}\text { Perceived ease of } \\
\text { use (PEOU) }\end{array}$} & - & - & 0.857 & 0.666 \\
\hline & PEOU1 & 0.817 & - & - \\
\hline & PEOU2 & 0.823 & - & - \\
\hline & PEOU3 & 0.809 & - & - \\
\hline \multirow{5}{*}{$\begin{array}{l}\text { Perceived attitude } \\
\text { (ATT) }\end{array}$} & - & - & 0.886 & 0.661 \\
\hline & ATT1 & 0.806 & - & - \\
\hline & ATT2 & 0.865 & - & - \\
\hline & АТT3 & 0.843 & - & - \\
\hline & ATT4 & 0.731 & - & - \\
\hline \multirow{3}{*}{$\begin{array}{l}\text { Perceived } \\
\text { resources (PR) }\end{array}$} & - & - & 0.902 & 0.822 \\
\hline & PR1 & 0.904 & - & - \\
\hline & PR3 & 0.909 & - & - \\
\hline \multirow{4}{*}{$\begin{array}{l}\text { Behavioural } \\
\text { intention }\end{array}$} & - & - & 0.930 & 0.770 \\
\hline & BI1 & 0.869 & - & - \\
\hline & $\mathrm{B} 12$ & 0.930 & - & - \\
\hline & $\mathrm{B} 13$ & 0.841 & - & - \\
\hline
\end{tabular}

CR, composite reliability; AVE, average variance extracted. 
constructs (Hair et al. 2017). Table 2 shows that all the HTMT values were under 0.9 , and all the square roots of AVE were higher than the inter-construct correlations (Garson 2016). The results confirm discriminant validity.

Overall, the indicator reliability, internal consistency reliability, convergent validity and discriminant validity tests conducted on the measurement model were satisfactory.

\section{Structural model assessment}

After confirming the suitability of the outer model, the inner model was examined. Before assessing the structural model, the variance inflation factor (VIF) was used to assess multicollinearity issues. Multicollinearity in ordinary least squares regression inflates standard errors, makes significance tests of exogenous latent variables unreliable and makes it difficult to assess the relative importance of one exogenous variable compared to another. The VIF values ranged from 1.715 to 2.196 . The VIF values were all less than 4 (Garson 2016) indicating that multicollinearity issues were not going to influence the model results.

Table 3 and Figure 2 summarised the inner model and the hypotheses testing results. Figure 2 shows the $R^{2}$ of the model. According to Chin (1998), the model explained moderate variances of $48 \%$ of perceived attitude towards the use, $60 \%$ of PU and $64 \%$ of the variance of rural-based STEM learners' and teachers' BI to use m-learning. This means that the total contribution of PEC, PEOU, ATT, PU, PR and PSI on learners' and teachers' BI to accept m-learning was $64 \%$. As recommended by Garson (2016), the significance level of the proposed hypotheses was tested using the bootstrapping procedure with 5000 subsamples, and the results are shown in Table 3. The significant level was set to 0.1 because of the exploratory nature of the study (Garson 2016). The results show that the only relations that were not supported were PR to ATT, PR to BI and PEOU to BI. Furthermore, Table 3 also shows the effect size $\left(f^{2}\right)$ of these relations. Three relations (PR to PU, ATT to BI and PEC to PU) had large effect sizes, two relations (PSI to ATT and PU to BI) had medium effect sizes, while the last eight had small effect sizes (Chin 1998). The blindfold method was adopted to assess the predictive relevance of the model (Hair et al. 2017). The $q^{2}$ values range from 0.248 to 0.568 , indicating a medium to large predictive relevance (Garson 2016; Hair et al. 2017). All the $q^{2}$ values were greater than zero indicating that the model can be used to predict teachers' and learners' acceptance of m-learning. The teachers' and learners' m-learning acceptance structural model consists of seven constructs. Perceived resources and PSI had a direct effect on PU, ATT and PEOU. Perceived ease to collaborate had a direct effect on PU. Perceived usefulness, ATT, PR and PEOU influenced BI.

To answer RQ2, a non-parametric multigroup analysis (MGA) was used to test if there was a significant difference between rural-based learners' and teachers' path coefficients. Table 4 shows the results of MGA.

TABLE 2: Heterotrait-Monotrait and Fornel-Larcker criterion.

\begin{tabular}{|c|c|c|c|c|c|c|c|c|c|c|c|c|c|c|}
\hline \multirow[t]{2}{*}{ Variable } & \multicolumn{7}{|c|}{ нТМт } & \multicolumn{7}{|c|}{ Fornel-Larcker criterion } \\
\hline & ATT & BI & PEC & PEOU & PR & PSI & PU & ATT & BI & PEC & PEOU & PR & PSI & PU \\
\hline ATT & - & - & - & - & - & - & - & $0.813 \dagger$ & - & - & - & - & - & - \\
\hline $\mathrm{BI}$ & 0.817 & - & - & - & - & - & - & 0.711 & $0.878 \dagger$ & - & - & - & - & - \\
\hline PEC & 0.519 & 0.557 & - & - & - & - & - & 0.409 & 0.463 & $0.899 \dagger$ & - & - & - & - \\
\hline PEOU & 0.692 & 0.526 & 0.454 & - & - & - & - & 0.556 & 0.439 & 0.351 & $0.816 \dagger$ & - & - & - \\
\hline PR & 0.618 & 0.554 & 0.402 & 0.892 & - & - & - & 0.500 & 0.467 & 0.311 & 0.694 & $0.907 \dagger$ & - & - \\
\hline PU & 0.611 & 0.751 & 0.874 & 0.531 & 0.510 & 0.830 & - & 0.530 & 0.677 & 0.719 & 0.441 & 0.428 & 0.646 & $0.803 \dagger$ \\
\hline
\end{tabular}

$\dagger$, The square roots of the average (AVE).

HTMT, Heterotrait-Monotrait; ATT, attitude; BI, behavioural intention; PEC, perceived ease to collaborate; PEOU, perceived ease of use; PR, perceived resources; PSI, perceived social influence; PU, perceived usefulness.

TABLE 3: Path coefficient.

\begin{tabular}{|c|c|c|c|c|c|c|c|}
\hline Relationship & Standard beta & Standard error & $t$ & $p$ & Decision & $f^{2}$ & VIF \\
\hline $\mathrm{ATT} \rightarrow \mathrm{BI}$ & 0.489 & 0.084 & 5.796 & 0.000 & Supported & $0.383 \dagger$ & 1.724 \\
\hline $\mathrm{PEC} \rightarrow \mathrm{PU}$ & 0.487 & 0.108 & 4.508 & 0.000 & Supported & $0.346 \dagger$ & 1.715 \\
\hline PEOU $\rightarrow$ ATT & 0.301 & 0.102 & 2.948 & 0.003 & Supported & $0.086 \S$ & 2.031 \\
\hline $\mathrm{PEOU} \rightarrow \mathrm{BI}$ & -0.089 & 0.090 & 0.985 & 0.325 & Not supported & $0.010 \S$ & 2.196 \\
\hline $\mathrm{PEOU} \rightarrow \mathrm{PU}$ & 0.167 & 0.066 & 2.539 & 0.011 & Supported & $0.058 \S$ & 1.196 \\
\hline $\mathrm{PR} \rightarrow \mathrm{ATT}$ & 0.098 & 0.111 & 0.882 & 0.378 & Not supported & $0.009 \S$ & 2.033 \\
\hline $\mathrm{PR} \rightarrow \mathrm{BI}$ & 0.108 & 0.095 & 1.138 & 0.256 & Not supported & $0.016 \S$ & 2.035 \\
\hline $\mathrm{PR} \rightarrow \mathrm{PEOU}$ & 0.647 & 0.052 & 12.492 & 0.000 & Supported & $0.691 \dagger$ & 1.194 \\
\hline $\mathrm{PSI} \rightarrow \mathrm{ATT}$ & 0.329 & 0.074 & 4.440 & 0.000 & Supported & $0.117 \S$ & 1.777 \\
\hline $\mathrm{PSI} \rightarrow \mathrm{PEOU}$ & 0.118 & 0.064 & 1.849 & 0.065 & Supported & $0.023 \S$ & 1.194 \\
\hline $\mathrm{PSI} \rightarrow \mathrm{PU}$ & 0.274 & 0.106 & 2.576 & 0.010 & Supported & $0.107 \S$ & 1.755 \\
\hline $\mathrm{PU} \rightarrow \mathrm{ATT}$ & 0.143 & 0.073 & 1.961 & 0.050 & Supported & $0.021 \S$ & 1.874 \\
\hline $\mathrm{PU} \rightarrow \mathrm{BI}$ & 0.411 & 0.069 & 6.000 & 0.000 & Supported & $0.316 t$ & 1.477 \\
\hline
\end{tabular}

$\dagger$, Large effect size; $\$$, medium effect size; $\S$, small effect size.

ATT, attitude; BI, behavioural intention; PEC, perceived ease to collaborate; PEOU, perceived ease of use; PR, perceived resources; PSI, perceived social influence; PU, perceived usefulness; VIF, variance inflation factor. 


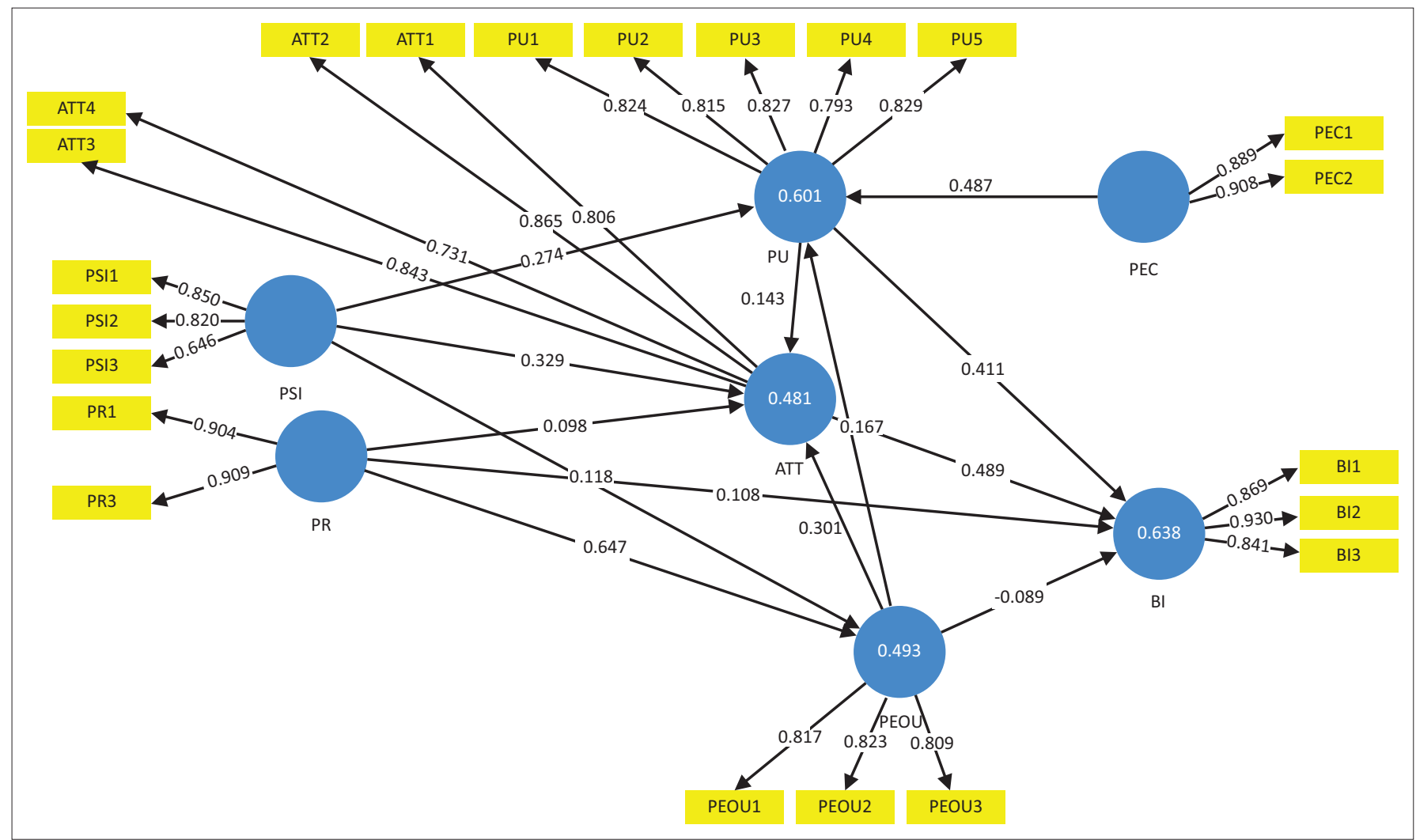

ATT, attitude; BI, behavioural intention; PEC, perceived ease to collaborate; PEOU, perceived ease of use; PR, perceived resources; PSI, perceived social influence; PU, perceived usefulness. FIGURE 2: Teachers' and learners' m-learning acceptance structural model.

TABLE 4: Multigroup analysis partial least squares results.

\begin{tabular}{lcc}
\hline Relationship & $\begin{array}{c}\text { Path coefficients difference } \\
\text { (learners - teachers) }\end{array}$ & $p$ (learners vs. teachers) \\
\hline $\mathrm{ATT} \rightarrow \mathrm{BI}$ & 0.003 & 0.489 \\
$\mathrm{PEC} \rightarrow \mathrm{PU}$ & 0.120 & 0.317 \\
$\mathrm{PEOU} \rightarrow$ ATT & 0.033 & 0.437 \\
$\mathrm{PEOU} \rightarrow \mathrm{BI}$ & 0.155 & 0.825 \\
$\mathrm{PEOU} \rightarrow \mathrm{PU}$ & 0.114 & 0.191 \\
$\mathrm{PR} \rightarrow \mathrm{ATT}$ & 0.114 & 0.297 \\
$\mathrm{PR} \rightarrow \mathrm{BI}$ & 0.065 & 0.639 \\
$\mathrm{PR} \rightarrow \mathrm{PEOU}$ & 0.035 & 0.624 \\
$\mathrm{PSI} \rightarrow \mathrm{ATT}$ & 0.151 & 0.809 \\
$\mathrm{PSI} \rightarrow \mathrm{PEOU}$ & 0.106 & 0.793 \\
$\mathrm{PSI} \rightarrow \mathrm{PU}$ & 0.126 & 0.715 \\
$\mathrm{PU} \rightarrow$ ATT & 0.222 & 0.940 \\
$\mathrm{PU} \rightarrow \mathrm{BI}$ & 0.208 & 0.062 \\
\hline
\end{tabular}

ATT, attitude; $B I$, behavioural intention; $\mathrm{PEC}$, perceived ease to collaborate; $\mathrm{PEOU}$, perceived ease of use; PR, perceived resources; PSI, perceived social influence; PU, perceived usefulness.

The results showed that all relationships differ insignificantly across the two groups (teachers and learners). This means that the same PLS structural path model applied to both teachers and learners.

\section{Discussion}

Research question 1 (RQ1): This study sought to examine the effects of rural-based STEM learners' and teachers' PEC, PSI, PU, PEOU, ATT and PR on their BI to use m-learning for learning STEM. The results showed that the model was appropriate for determining rural high school learners' and teachers' acceptance of m-learning, as it explained $64 \%$ of the variance in BI. The variance explained was considered to be moderate (Chin 1998). It was found that all the antecedents predict BI to use m-learning. However, the current results are consistent with the findings of Saroia and Gao (2019) who found that only PU and ATT have a direct effect on BI. A plausible reason might be that rural-based STEM learners' and teachers' BI to use m-learning was reinforced by their positive feelings and the utility of m-learning. Therefore, m-learning platforms need to contain as much learning and assessments material as possible.

Contrary to the findings of Davis (1989), this study found that PEOU (H6: $\beta=0.301, p<0.05)$ predicts ATT, better than PU (H2: $\beta=0.143, p<0.05)$. This shows that rural-based STEM teachers and learners consider the utility less important than the effort required for learning to use m-learning for STEM teaching and learning. This also shows that if m-learning is proved to be easy to use, rural-based STEM teachers and learners are more likely to adopt it for STEM teaching or learning. It is interesting to note that PEOU (H5: $\beta=-0.089, p>0.05$ ) does not have a direct effect on BI. This might mean that both rural-based STEM teachers and learners do not perceive ease of use as a critical factor they consider important when accepting m-learning. Perceived ease of use has a direct positive influence on both ATT and PU (Venkatesh \& Davis 2000). The result that PEOU directly affects ATT is consistent with Saroia and Gao (2019). It is reasonable to infer that the effort needed to learn to use 
m-learning positively affects rural STEM teachers' and learners' attitude towards the use. Contrary to the findings of Saroia and Gao (2019) findings, PEOU (H4: $\beta=0.167, p<0.05)$ directly influences PU. This means that for both rural-based STEM teachers and learners, the utility of m-learning is promoted by less perceived effort required to learn to use the system. This finding might relate to participants in this study, who were in an examination-class, teaching or learning STEM-related subjects, which are considered difficult. Any m-learning platform that is difficult to learn increases the pressure on them, and the likelihood that they will not utilise it. Therefore, m-learning developers need to develop m-learning platforms that are easy to use.

Perceived social influence had a direct positive effect on PU (H10: $\beta=0.274, p<0.05)$, ATT (H11: $\beta=0.329, p<0.05$ ) and PEOU (H12: $\beta=0.118, p<0.05)$. Perceived social influence has already been found to influence PU (Nikou \& Economides 2018). Our results imply that when rural-based STEM learners and teachers know that their colleagues, school management, parents and educational authorities approve of and perceive the benefits of m-learning, they perceive it as useful and easy to learn. Additionally, the finding implies that rural-based STEM teachers and learners value the voices of people important to them concerning the learning of STEM using m-learning. Therefore, the Department of Basic Education should provide teachers and learners with an awareness of the potential benefits of m-learning for STEMrelated subjects.

The results showed that PR (H8: $\beta=0.647, p<0.05)$ had a positive effect on PEOU, and this result is in-line with the finding of Nikou and Economides (2018). The availability of resources enhances the ease of use of m-learning. It is interesting to note that PR does not affect ATT (H9: $\beta=0.098$, $p>0.05)$ and $\mathrm{BI}(\mathrm{H} 7: \beta=0.108, p>0.05)$. This means that the scarcity of resources does not affect rural-based STEM teachers' and learners' acceptance of m-learning. A reasonable reason for that is that the respondents were an examinationclass, and they perceived the benefits of m-learning more important than the cost involved. Examination-classes are always under pressure to perform and as a result, anything that can improve learners' performance is welcomed. Perceived resources might not have a direct effect on acceptance of m-learning, but rather it has an impact on its actual use. Thus, for a successful implementation of m-learning for STEM learning, resources need to be provided in rural areas.

Perceived ease to collaborate (H13: $\beta=0.487, p<0.05$ ) positively influences PU. The usefulness of m-learning is determined by how easy it is for teachers and learners to collaborate. M-learning platforms that enable teachers and learners to easily work together are most likely to be perceived useful.

Research Question (RQ2): Our results showed that there was no significant difference between teachers' and learners' path coefficients. This is in contradiction to the findings of
(Osakwe et al. 2017) who found that learners were more positive towards m-learning than their teachers. However, our results showed that the structural model can be used to predict m-learning acceptance for both teachers and learners. This means that teachers and learners consider the same factors when accepting m-learning.

\section{Recommendations}

Based on the results of this study, the following recommendations can be made to mobile developers and the DBE:

- Mobile developers should make m-learning platforms that contain as much STEM learning material and assessment as possible.

- Additionally, the platforms should be user-friendly. This is primarily because the utility and ease of use are considered important when adopting m-learning by rural-based STEM teachers and learners.

- The DBE should provide awareness workshops on the usefulness of m-learning for STEM learning.

- Additionally, the DBE should provide the infrastructure that can support m-learning. This is because for both teachers and learners the availability of resources affects their ease of use, which in turn affects their attitude towards and the usefulness of m-learning.

One limitation of this study is that it focused on rural areas only. Consequently, the generalisation of the findings of this study to all high schools both in rural areas and urban should be done with caution. Future studies should replicate this study in urban areas and compare the findings. It will be interesting to carry the same study in the same area but using learners and teachers of other subjects that are not STEMrelated and considering other classes which are not an examination class.

\section{Conclusion}

The model explained $64 \%$ of rural high school STEM teachers' and learners' BI to use m-learning. The results confirm the findings of Davis (1989) that learners' and teachers' PEOU influences both ATT and PU, which in turn affect their BI. Furthermore, the results support the suggestion by Venkatesh et al. (2003) who proposed that external variables of TAM need to be identified and examined to ensure that TAM is a feasible model for the context. In this study, PSI, PEC and PR were added to TAM. The results showed that the TAM can be used to predict the acceptance of m-learning. Additionally, the added variables had an indirect effect on rural-based STEM teachers' and learners' BI to use m-learning. According to Garson (2016) predictive relevance; $q^{2}$ values of PSI, PEC and PR were considered large, meaning that the added constructs are important in predicting rural-based STEM learners' and teachers' adoption of m-learning in rural areas. The lessons that can be drawn from this study are that rural high school STEM teachers' and learners' needs are similar when it comes to the adoption of m-learning. Teachers and learners consider the utility and attitude towards the use as 
the most important factors when adopting m-learning. Furthermore, awareness campaigns, infrastructure, mobile devices and data need to be made available for mobile learning to be successfully adopted in rural areas.

\section{Acknowledgements}

The authors would like to thank Constance Chiza and Nenyasha Mutambara for their support and encouragement.

\section{Competing interests}

The authors have declared that no competing interests exist.

\section{Author's contributions}

All authors contributed equally to this work.

\section{Funding Information}

This research received no specific grant from any funding agency in the public, commercial or not-for-profit sectors.

\section{Data availability statement}

The datasets generated during and/or analysed during this study are available from the corresponding author on reasonable request.

\section{Disclaimer}

The views and opinions expressed in this article are those of the authors and do not necessarily reflect the official policy or position of any affiliated agency of the authors.

\section{References}

Al-dheleai, Y.M., Baki, R., Tasir, Z. \& Al-rahmi, W.M., 2019, 'What hinders the use of ICT among academic staff at Yemen's public universities?', International Journal of Humanities and Innovation (IJHI) 2(1), 7-12. https://doi.org/10.33750/ijhi. v2i1.30

Alrajawy, I., Daud, N.M., Isaac, O. \& Mutahar, A.M., 2017, 'Examine factors influencing the intention to use mobile learning in Yemen public universities', Asian Journal of Information Technology 16(2), 287-297.

Alshmrany, S. \& Wilkinson, B., 2017, 'Factors influencing the adoption of ICT by teachers in primary schools in Saudi Arabia', Education (Mohe) 27, 143-156. https://doi.org/10.14569/IJACSA.2017.081218

Alrajawy, I., Isaac, O., Ghosh, A., Nusari, M., Al-Shibami, A.H. \& Ameen, A.A., 2018 'Determinants of Student's intention to use Mobile learning in Yemeni public universities: Extending the technology acceptance model (TAM) with anxiety', universities: Extending the technology acceptance model (TAM) with
International Journal of Management and Human Science 2(2), 1-9.

Bazelais, P. \& Doleck, T., 2018, 'Investigating the impact of blended learning on academic performance in a first semester college physics course', Journal of
Computers in Education 5(1), 67-94. https://doi.org/10.1007/s40692-018-0099-8

Bosman, A. \& Schulze, S., 2018, 'Learning style preferences and Mathematics achievement of secondary school learners', South African Journal of Education 38(1), 1-8. https://doi.org/10.15700/saje.v38n1a1440

Bourgonjon, J., Valcke, M., Soetaert, R. \& Schellens, T., 2010, 'Students' perceptions about the use of video games in the classroom', Computers and Education 54(4), 1145-1156. https://doi.org/10.1016/j.compedu.2009.10.022

Cheng, E.W., 2019, 'Choosing between the theory of planned behavior (TPB) and the technology acceptance model (TAM)', Educational Technology Research and Development 67(1), 21-37. https://doi.org/10.1007/s11423-018-9598-6

Chin, W.W., 1998, The partial least squares approach for structural equation modeling Lawrence Erlbaum Associates, Hillsdale, NJ.

Creswell, J.W., 2013, Research design: Qualitative, quantitative, and mixed methods, Sage, Los Angeles, CA.

Criollo-C, S., Luján-Mora, S. \& Jaramillo-Alcázar, A., 2018, 'Advantages and disadvantages of M-learning in current education', in 2018 IEEE World Engineering Education Conference (EDUNINE), pp. 1-6, March, IEEE.
Davis, F.D., 1989, 'Perceived usefulness, perceived ease of use, and user acceptance of information technology', MIS Quarterly 13(3), 319-340. https://doi.org/ of information
$10.2307 / 249008$

Demir, K. \& Akpinar, E., 2018, 'The effect of mobile learning applications on students' academic achievement and attitudes toward mobile learning', Malaysian Online Journal of Educational Technology 6(2), 48-59. https://doi.org/10.17220/mojet. 2018.02.004

Dillenbourg, P. (ed.), 1999, 'What do you mean by collaborative learning?', in Collaborative learning: Cognitive and computational approaches, pp. 1-19, Elsevier, Oxford.

Fang, C.S.O.Y., Kayad, F. \& Misieng, J., 2019, 'Malaysian undergraduates' behavioura intention to use LMS for online English learning: An extended Self-Directed Learning Technology Acceptance Model (SDLTAM)', Journal of ELT Research 4(1) 8-25. https://doi.org/10.22236/JER_Vol4Issue1pp8-25

Fishbein, M. \& Ajzen, J., 1975, Beliefs, attitudes, intention, and behavior: An introduction of theory and research reading, Addison Wesley Publishing, Reading, MA.

Force, S.T., 2014, Innovate: A blueprint for science, technology, engineering, and mathematics in California public education, Californians Dedicated to Education Foundation, Dublin, CA

Ford, M. \& Botha, A., 2010, 'A pragmatic framework for integrating ICT into education in South Africa', in 2010 IST-Africa, May 19, 2010, pp. 1-10, IEEE, Durban, South Africa.

Garson, G.D., 2016, Partial least squares: Regression \& structural equation models, Statistical Publishing Associates, Asheboro, NC.

Hair, J.F., Hult, G.T.M., Ringle, C.M. \& Sarstedt, M., 2017, A primer on partia least squares structural equation modeling (PLS-SEM), Sage Publications, Los Angeles, CA.

Joo, Y.J., Kim, N. \& Kim, N.H., 2016, 'Factors predicting online university students' use of a mobile learning management system (m-LMS)', Educational Technology Research and Development 64(4), 611-630. https://doi.org/10.1007/s11423-0169436-7

Li, R., Meng, Z., Tian, M., Zhang, Z., Ni, C. \& Xiao, W., 2019, 'Examining EFL learners' individual antecedents on the adoption of automated writing evaluation in China', Computer Assisted Language Learning 32(7), 784-804. https://doi.org/10.1080/ 09588221.2018.1540433

Lim, C.P. \& Khine, M., 2006, 'Managing teachers' barriers to ICT integration in 'Singapore schools', Journal of Technology and Teacher Education 14(1), 97-125.

Liu, S.H., 2016, 'The perceptions of participation in a mobile collaborative learning among pre-service teachers', Journal of Education and Learning 5(1), 87-94. https://doi.org/10.5539/jel.v5n1p87

MacCallum, K. \& Jeffrey, L., 2014, 'Factors impacting teachers' adoption of mobile learning', Journal of Information Technology Education 13, 141-162. https://doi. org/10.28945/1970

Mathieson, K., Peacock, E. \& Chin, W.W., 2001, 'Extending the technology acceptance model: The influence of perceived user resources', ACM SIGMIS Database: The DATABASE for Advances in Information Systems 32(3), 86-112. https://doi.org/ 10.1145/506724.506730

Mboweni, L., 2014, 'Challenges and factors contributing to learner absenteeism in selected primary schools in Acornhoek', Doctoral dissertation, University of South Africa.

Mutambara, D. \& Bayaga, A., 2020, 'Understanding rural parents' behavioral intention to allow their children to use mobile learning', in Conference on e-Business, $e$-Services and e-Society, April 06, 2020, pp. 520-531, Springer, Cham.

Nikou, S.A. \& Economides, A.A., 2018, 'Mobile-based micro-learning and assessment: Impact on learning performance and motivation of high school students', Journal of Computer Assisted Learning 34(3), 269-278. https://doi.org/10.1111/jcal. 12240

Osakwe, J.O., Nomusa, D. \& Jere, N., 2017, 'Teacher and learner perceptions on mobile learning technology: A case of Namibian high schools from the Hardap Region', Online Submission 1(1), 13-41. https://doi.org/10.26762/he.2017.30000002

Padmanathan, Y. \& Jogulu, L.N., 2018, 'Mobile learning readiness among Malaysian Polytechnic students', Journal of Information Systems and Technology Management 3(8), 113-125.

Sánchez-Prieto, J.C., Hernández-García, Á., García-Peñalvo, F.J., Chaparro-Peláez, J. \& Olmos-Migueláñez, S., 2019, 'Break the walls! Second-order barriers and the acceptance of mLearning by first-year pre-service teachers', Computers in Human Behavior 95, 158-167. https://doi.org/10.1016/j.chb.2019.01.019

Saroia, A.I. \& Gao, S., 2019, 'Investigating university students' intention to use mobile learning management systems in Sweden', Innovations in Education and Teaching International 56(5), 569-580. https://doi.org/10.1080/14703297.201 8.1557068

Siegel, D.M., 2008, 'Accepting technology and overcoming resistance to change using the motivation and acceptance model', Doctor of Philosophy, University of Central Florida.

Sivo, S.A., Ku, C.H. \& Acharya, P., 2018, 'Understanding how university student perceptions of resources affect technology acceptance in online learning courses', Australasian Journal of Educational Technology 34(4), 72-91. https://doi.org/ 10.14742/ajet.2806

Siyam, N., 2019, 'Factors impacting special education teachers' acceptance and actual use of technology', Education and Information Technologies 24(3), 2035-2057. https://doi.org/10.1007/s10639-018-09859-y

Teo, T., Lee, C.B. \& Chai, C.S., 2008, 'Understanding pre-service teachers' computer attitudes: Applying and extending the technology acceptance model', Journal of Computer Assisted Learning 24(2), 128-143. https://doi.org/10.1111/j.1365Computer Assisted
2729.2007.00247.x 
Venkatesh, V., 2000, 'Determinants of perceived ease of use: Integrating control, intrinsic motivation, and emotion into the technology acceptance model', intrinsic motivation, and emotion into the
Information Systems Research 11(4), 342-365.

Venkatesh, V. \& Davis, F.D., 2000, 'A theoretical extension of the technology acceptance model: Four longitudinal field studies', Management Science 46(2), 186-204. https://doi.org/10.1287/isre.11.4.342.11872
Venkatesh, V., Morris, M.G., Davis, G.B. \& Davis, F.D., 2003, 'User acceptance of information technology: Towards a unified view', MIS Quarterly 27(1), 425-478. https://doi.org/10.1287/mnsc.46.2.186.11926

Visser, M., Juan, A. \& Feza, N., 2015, 'Home and school resources as predictors of mathematics performance in South Africa', South African Journal of Education 35(1), 1-10. https://doi.org/10.15700/201503062354 